\title{
Waiting: The Experience of Persons in a Critical Care Waiting Room
}

\author{
Debra A. Bournes, ${ }^{1} *$ Gail J. Mitchell, ${ }^{2 \dagger}$ \\ ${ }^{1}$ School of Nursing, York University, Toronto, Ontario, Canada \\ ${ }^{2}$ Sunnybrook \& Women's College Health Sciences Centre, University of Toronto, Toronto, \\ Ontario, Canada \\ Received 20 September 2000; accepted 9 September 2001
}

\begin{abstract}
The purposes of this study were to discover the essences of the experience of waiting, to provide new knowledge about what it is like to wait, and to contribute to nursing knowledge. Participants were 12 persons who were family members or friends of persons in an adult critical care unit. The Parse research method was used to answer the research question: What is the structure of the lived experience of waiting? The central finding of this study was this structure: The lived experience of waiting is a vigilant attentiveness surfacing amid an ambiguous turbulent lull as contentment emerges with uplifting engagements. The structure is discussed in relation to nursing knowledge and in relation to how it can inform future research and practice. (c) 2002 John Wiley \& Sons, Inc. Res Nurs Health 25:58-67, 2002
\end{abstract}

\section{Keywords: critical care; human becoming; Parse method; phenomenological-} hermeneutic research; waiting

Waiting is a common human experience. All people experience having to wait at some time in their lives-for the arrival of a new baby, for a meeting with an old friend, for the beginning of a new project, "for their hair to grow ... for a pot to boil ... or ... for wind to fly a kite" (Seuss, 1990). People also experience having to wait for events they consider difficult - for taking a risky test, for saying good-bye to a loved one, or for hearing bad news. Waiting is a universal experience that everyone can describe in some personal way in relation to their own lives. Experience has taught the current authors that waiting is a particularly vivid experience for persons who have a loved one who is critically ill. Family and friends of patients in a critical care unit spend hours, days, and even months waiting for news about what is happening. Increased knowledge about indivi- duals' perspectives of what it is like to wait while someone they care about is separated from them and experiencing a critical life situation is essential to providing meaningful health care services.

Waiting has been associated with diminished satisfaction with health care services (Bruce, Bowman, \& Brown, 1998; Rondeau, 1998). It has also been described as an anguishing doubt and uncertainty (Bunzel, Wollenek, \& Grundbock, 1992; Ruppert, 1992) that is isolating, distressing (Bright, Craven, \& Kelley, 1990), and frustrating (Dube, Schmitt, \& Leclerc, 1991). Some people say that waiting is "like living in a time bomb" (Suszycki, 1988, p. 207). Others talk about "feeling guilty" when they cannot constantly be available for a family member who is waiting (Bright et al.). Although no research has focused on the experience of waiting for persons with a friend or

Correspondence to Debra A. Bournes, 1998 Kempton Park Drive, Mississauga,

Ontario L5M 2Z3, Canada.

*Assistant Professor.

${ }^{\dagger}$ Chief Nursing Officer. 
family member in a critical care unit, researchers have investigated the perceived needs of family members in a critical care waiting room (Warren, 1993); the meaning of caring behaviors in the critical care waiting room (Warren, 1994); and the experience of critical injury from spouses' perspectives (Leske, 1992; Ruppert). These researchers found that families in critical care waiting rooms describe feeling numb, hoping for improvement, being afraid, having no control, walking around like a robot, and feeling powerless (Leske). They also found that people in critical care waiting rooms expect information (Warren, 1994), assurance, support, and comfort (Warren, 1993) from professionals who provide equitable, dignified, and respectful care (Waters, 1999). Enhancing understanding about what it is like to wait in a critical care waiting room may help hospital staff provide services that individuals say are helpful when they have to wait.

The purposes of this study were: to discover the essences of the experience of waiting for persons who have family members or friends in a critical care unit; to provide new knowledge about what it is like to wait that can be used as a guide in research and practice; and to contribute to knowledge about human becoming - the nursing perspective underpinning this study.

\section{NURSING PERSPECTIVE}

The nursing perspective for this study was Parse's $(1981,1998)$ theory of human becoming. Research guided by human becoming focuses on enhancing understanding of persons' perspectives of universal lived experiences like waiting. From this perspective the meaning of life experiences, the relationships created, the patterns lived, and the choices made in light of imagined hopes and dreams shape human health and quality of life. For Parse $(1981,1990,1998)$ health is the way people go on and live what is important to them, moment to moment and day to day (Parse, 1990, 1998). Quality of life is what people say their life is like (Parse, 1994). The goal of nursing guided by the human becoming theory is to participate with persons in ways that make a difference to quality of life from the person's perspective (Parse, 1981, 1998). People who are waiting in critical care can help health professionals understand what that experience is like so that professionals can be with them in ways that are helpful. Parse $(1981,1998)$ has suggested that people know what might be helpful and that they know the best way, for them, to go forward during difficult times.

The three principles of the human becoming theory provide a lens through which to interpret the findings that were discovered from the participants' descriptions of lived experiences. The first principle is "structuring meaning multidimensionally" (Parse, 1998, p. 35). It relates to the way humans continuously assign significance to their experiences-both explicitly and tacitly. The meaning individuals give to their experiences is shaped by their personal knowledge and value priorities. The second principle, "cocreating rhythmical patterns of relating" (Parse, 1998, p. 42), is about the ways humans live rhythmical patterns of relating with others, ideas, objects, and situations that are paradoxical in nature and cocreated with the universe. The third principle of human becoming, "cotranscending with the possibles" (Parse, 1998, p. 46), refers to the ways humans change and unfold in life as they reach beyond what was and is with what is not yet (Parse, 1981, 1998).

Interpreting the findings in light of the theoretical principles of human becoming provides another way of looking at the findings that adds depth and clarity to the description of the lived experience under study. In this study it enhances understanding of the lived experience of waiting in ways that are helpful for thinking about human health and for understanding experiences that shape quality of life for persons with a family member or a friend who is critically ill.

\section{RESEARCH METHOD AND DESIGN}

Parse's phenomenological-hermeneutic method (Parse, 1987, 1998) was used to answer the research question: what is the structure of the lived experience of waiting? The word structure, taken from phenomenology, means definition or description. It is the "paradoxical living of the remembered, the now moment, and the notyet... incarnated all-at-once in the participants' descriptions" (Parse, 2001, p. 170). The Parse research method generates a structure of universal lived experiences of health through the processes of participant selection, dialogical engagement, extraction-synthesis, and heuristic interpretation (Parse, 1987, 1998, 2001). Protection of participants' rights is integral to the Parse method-thus, measures that were taken to ensure participants' rights were protected are addressed in this section. 


\section{Participant Selection and Protection of Participants' Rights}

Participants in this study were 10 women and 2 men over 18 years of age who agreed to speak with the researchers about their experience of waiting. They were either a mother, father, wife, husband, or daughter of a person admitted to an 18-bed adult medical-surgical critical care unit in a large university-affiliated teaching hospital in Canada. The patients were in critical care for a variety of reasons-including traumatic injuries, complicated surgical procedures, and medical emergencies. The participants were recruited from the critical care waiting room. A printed pamphlet about the study was distributed in the waiting room. In addition, a social worker from critical care brought the study to the attention of persons who expressed having to struggle with waiting. Persons who were interested contacted the researchers, either by phone or through the social worker. The study was approved by the institution's research ethics committee, participants signed consent forms, and standard measures were taken to protect their rights.

\section{Dialogical Engagement (Data Gathering)}

Dialogical engagement is an intersubjective process whereby the researcher lives true presence with the participant. The researcher moves in rhythm with the participant's description of the phenomenon of concern (Parse, 1987, 1998, 2001). In this study the researchers initiated the dialogical engagements by saying, "Please tell me about your experience of waiting." The researchers then attended to each participant's description. No other questions were asked, although the participants were sometimes encouraged to go on or to speak about how some things they said related to their experience of waiting. The audiotaped dialogues, which lasted 20-40 min, were transcribed for the extraction-synthesis process.

\section{Extraction-Synthesis (Analysis-Synthesis)}

Extraction-synthesis is the process of moving the descriptions from the language of the participants across levels of abstraction to the language of science (Parse, 1987, 1998, 2001). It includes: extracting and synthesizing stories and essences (core ideas) from the transcribed descriptions in the participants' language; conceptualizing the essences in the language of the researcher; synthesizing a proposition from the essences of each participant's description; extracting and synthesizing core concepts (ideas that capture the central meaning of the propositions); and synthesizing a structure (a statement conceptualized by the researcher that joins the core concepts) of the lived experience (Parse, 1987, 1998, 2001). The structure as evolved answers the research question.

For example, stories are extracted-synthesized summaries that reflect the core ideas and examples that each of the participants shared about their experiences of waiting. They are written using excerpts from the dialogical engagement with each participant. The following is Dina's story.

"Waiting is hard," Dina said. "In the beginning I was worried and anxious and I lost track of the days." She shared that the first few days her father was in critical care, when they were not sure what was happening, she "couldn't focus on anything." She said, "I just sat there, wondering and worrying about what was taking so long... [and] when they were going to call me to go back in and visit." Dina and her family spent two nights in the waiting room. "Those were brutal," she said. "The night waiting is completely different than the day because it's dark and it's quieter.... You start to think the worst, and you keep expecting to hear that something terrible has happened." Although "you're trying to sleep, and you're just exhausted, you're always anticipating this horrible event." When she spent nights at home, Dina experienced a "sense of urgency" as she was "getting ready to come back in the morning." She added, "When you are at the hospital, there is not that same sense of urgency because you don't have to be somewhere else. You are where you have to be." Dina said she had "completely forgotten what it is like to shop ... or to hang out with friends. You have to give up that control and just stay put and wait." It is "like you start to forget there is a world outside. You know it is not going to go on forever... and right now you have to stay nearby-it's just the way it is." For Dina the experience of waiting "depends on what's going on with my dad.... It's more stressful the days that he's taken a turn for the worse." It is then that "being there is more frustrating." Dina added, "You know it is a good day when there are signs of improvement." She said, "I am getting used to the waiting now that I know the ropes." Having a volunteer in the 
waiting room helps. She shared that "you feel a bit more in control if there is a volunteer there to answer the phone, and to phone in and see if you can go back in and visit.... We're almost intimidated [to do it ourselves]... because we don't want to bug them." Dina found that reading and going for lunch helped to pass the time. "It takes your mind away ... and it helps you, not to forget, but to get a little break-because it never leaves your thoughts." Dina was thankful to have her family and friends there to talk to: "Any kind of conversation, any interaction what-so-ever passes the time." She offered, "I feel good about sharing my experiences" with other people in the waiting room. When "I see people sitting by themselves, I kind of take them under my wing, and let them know what I have learned about how the place works." The days go by "pretty fast." Dina conveyed that "ultimately, you want to be with your family member as much as possible," but you spend "most of the day in the waiting room" because you go in and then they "ask you to leave whenever someone is having something done."

The essences extracted-synthesized in the participant's language represent the core ideas pertaining to the experience of waiting that were shared in the dialogical engagement process and captured in the participant's story. The essences in the researcher's language are expressions of the key ideas contained in the participants' language conceptualized at a more abstract level. Examples of essences at both levels of abstraction are shown in Table 1.

The above process was completed for all participants, and then the researchers created propositions for each participant. Propositions, nondirectional statements, join the core ideas from the essences. For Dina the proposition is: Waiting is lethargy emerging with the tormenting incertitude of anticipating the foreboding with vigilant attentiveness, as contentment surfaces while appreciating uplifting engagements, and seasoned insightfulness arises while yielding with temporary abeyance.

Three core concepts were extracted and synthesized from the 12 propositions. The core concepts are the central ideas about the lived experience of waiting that were described, in some way, by all participants. The core concepts are expressed at an abstract level because they capture diverse descriptions of experiences that were interpreted by the researchers as similar ideas (Parse, 1998, 2001). Specifying findings of phenomenological studies at an abstract level is congruent with the essential processes of the phenomenological method set forth by Spiegelberg $(1960 / 1965,1975,1976)$ and further developed by van Kaam $(1959,1966)$ and Giorgi $(1985,1989,1997)$. When synthesized and joined together, the core concepts form the structure: The lived experience of waiting is a vigilant attentiveness surfacing amid an ambiguous turbulent lull as contentment emerges with uplifting engagements. The structure, as evolved from the participants' descriptions, answers the research question.

\section{Heuristic Interpretation}

Heuristic interpretation is the process of integrating the structure of the lived experience with the human becoming theory. It involves two

Table 1. Example of Extracted-Synthesized Essences for One Participant (Dina)

\begin{tabular}{|c|c|}
\hline Participant's Language & Researcher's Language \\
\hline $\begin{array}{l}\text { Waiting is brutal, stressful, and frustrating. It is being } \\
\text { unsure what is happening, feeling intimidated, expecting } \\
\text { something terrible, being unable to focus, losing track } \\
\text { of day, and being exhausted. It is wanting to stay nearby } \\
\text { and experiencing a sense of urgency when at home since } \\
\text { what is happening never leaves your thoughts. }\end{array}$ & $\begin{array}{l}\text { Lethargy emerges with the tormenting } \\
\text { incertitude of anticipating the } \\
\text { foreboding with vigilant attentiveness }\end{array}$ \\
\hline $\begin{array}{l}\text { Waiting is being thankful to have family and friends to talk } \\
\text { to, feeling good about sharing experiences, and doing things } \\
\text { to get a little break and help the days go by fast. It is } \\
\text { knowing it is a good day when there are signs of improvement } \\
\text { and feeling more in control when there is a volunteer who } \\
\text { can phone in to see if it is all right to go back in and visit. }\end{array}$ & $\begin{array}{l}\text { Contentment surfaces while } \\
\text { appreciating uplifting engagements. }\end{array}$ \\
\hline $\begin{array}{l}\text { Waiting is forgetting the world outside while iust staying put. } \\
\text { It is learning the ropes, getting used to it, and knowing it } \\
\text { will not be forever, but that right now it is iust the way it is. }\end{array}$ & $\begin{array}{l}\text { Seasoned insightfulness arises while } \\
\text { yielding with temporary abeyance. }\end{array}$ \\
\hline
\end{tabular}


processes: structural transposition and conceptual integration (Parse, 1987, 1998, 2001). Structural transposition is moving the structure of the lived experience up another level of abstraction. Conceptual integration further specifies the structure of the lived experience at the level of the theory. Discussion of the structure of waiting in light of its theoretical connections provides a way of further explicating the core concepts. It also enhances understanding of the nursing perspective guiding this study by providing concrete examples of the meaning of theoretical concepts that can be readily connected with research and practice endeavors.

\section{RESULTS}

The central finding of this study was the structure: The lived experience of waiting is a vigilant attentiveness surfacing amid an ambiguous turbulent lull as contentment emerges with uplifting engagements. This structure is comprised of three core concepts-vigilant attentiveness, ambiguous turbulent lull, and contentment with uplifting engagements - that reflect the unitary experience of waiting for the participants in this study. Below, each core concept is described and supported with quotes from the participants.

\section{Vigilant Attentiveness}

The first core concept, vigilant attentiveness, captures the participants' descriptions of waiting as a focused, persistent, and diligent watchfulness. Participants talked about things like "not wanting to go too far away-just in case," "being there to see he is still breathing," "being on pins and needles and jumping every time the phone rings," "looking at your watch every half a second," and "running back when they should be telling you something." The participants also described "always anticipating a horrible event," "a sense of urgency to get back" when they were not close to their loved one, and constantly "thinking about it" and "calling and calling." For example, one participant shared, "It never leaves your thoughts"; whereas someone else said, "When I go home at night, I can't go to sleep. I've got to get back in there." Another participant offered, "We just seem to get home, and as soon as we get there, we phone and then we sit and talk about what they said. We just kind of wait for the morning to get back there and get back in the groove." Similarly, one participant shared, "The night waiting is completely different than the day because it's dark and quieter.... You start to think the worst, and you keep expecting to hear that something terrible has happened."

The words of other participants also illustrate the core concept of vigilant attentiveness. For example, one participant said, "They certainly answer my questions if I ask them, but there are so many things going on in my head-my mind is going a mile a minute. Last night I woke up five times thinking about it. Sometimes when I am on my way in to see my husband, I can hardly catch my breath." Another participant, who had a son in critical care for more than a month, described the "guilt" she felt when she forgot about the situation for a few minutes. She said, "I remember going shopping one day, and as I was walking through the store, I forgot. Then all of the sudden something triggered me to remember, and there was this guilt."

\section{Ambiguous Turbulent Lull}

The second core concept, ambiguous turbulent lull, captures the ways participants in this study described waiting as a grueling experience of unsure stillness. When they talked about their experiences of waiting, the participants each shared details about the turmoil that they had to endure while living with not knowing what would happen and feeling like their lives were on hold. They described the waiting as "distressing," "horrible," "frustrating," "stressful," "brutal," and "difficult-like an emotional hell." Some of them said it was "like living in terror." Another participant described experiencing a "helpless feeling" because "there was nothing that you could do to change what happened." The participants also described being "paralyzed," "zombielike," "nonfunctioning," and "numb." One person said, "The worst part of waiting is the unknown." Another offered,

Waiting is such an unknown quantity. It's horrendousyou're almost suspended. It's like you're frightened and hopeful at the same time. It's all those mixed up emotions-fear and uncertainty and worry and tension. You almost feel numb, and you get terribly tired because all this energy is being spent in worry and concern.

\section{Another participant said,}

The big thing about waiting is not knowing. Sometimes we just sat there for days, and it seemed we were 
getting no information at all. Your mind does all kinds of things_-it's a real whirlwind. Generally, I have no concept of time-it absolutely stands still and yet it goes fast. It goes slow in that I am waiting to see progress, and that's slow. It goes fast in that it's supper time already, and I've been here all day.

Similarly, the core concept ambiguous turbulent lull is evident in descriptions given by other participants who also mentioned the notion of time. For example, one person said, "It was like time had stopped;" and another said, "While we were waiting for the surgery to be over, I looked at my watch and thought, 'Oh, it must have stopped.' I don't think the staff have any idea of what it is like to be waiting to find out how serious the results are or what it is like to be asked to go out when you are not told what they are going to do. The not knowing is unbearable." One woman, who was waiting for her husband's surgery to end, shared,

It is a great burden. If something goes wrong, I may wonder if I should have said no. I feel responsible and so helpless. There's a line in the poem 'In Flanders' Field" that is something like: "They also serve who only stand and wait." It keeps going through my head because I felt like I wasn't serving any useful purpose just waiting. It's really — until you live through it, you can't imagine how awful it is. There aren't really words to describe it, there really aren't. Waiting is as if somebody's got a hold of your heart, and they're just kind of squeezing it, you know. There's such a level of anxiety, and it goes on and on. It is pain. It's like mental anguish. The worst waiting is being out in the waiting room not able to do anything.

The same person added,

It's just that normal life is going on while yours is kind of on hold while you're dealing with this tragedy. The people that work here have been home and they're talking about parties and they're sharing their family experiences, and I find that affects my anxiety level. I have a feeling of wanting everyone to go "Sssshhhh, quiet, it's a sick room." I even found the Christmas decorations disturbing. It's hard to explain that your life is stopped and everything around you seems to move on anyway, and it's troubling. Time passes very slowly when you are waiting.

\section{Contentment With Uplifting Engagements}

The third core concept, contentment with uplifting engagements, captures the ways participants in this study described calming and comforting experiences of helpful associations with others and activities while waiting. As they spoke about their experiences of waiting, the participants all described, for instance, "feeling better," "being up," "feeling good," "getting strength," and "feeling positive" when they could "share their experiences," "do little things," "follow blood tests," or "just see, say hi, and look into the eyes" of their loved one. Simultaneously, they also talked about activities and relationships that were "healing" and that helped them feel more "in control," "at ease," "joy," "pleasure," and "grounded." For example, one person shared, "I have to tell myself to quiet down. I take deep breaths to get myself down." Others said, "When she gave me the news, I could breathe-it was a big help," and "It is easier to wait at the hospital because when he's awake we can come in and see him and talk to him, and he responds and then you feel good." Someone else offered,

When they give us signs to watch for, it is kind of helpful because at least you can say, "OK, he's doing this and he's doing that." So, right now I am waiting for signs. Knowing what to call progress makes watching and waiting a lot easier. Some staff let us help with little things-like washing his hair or creaming his hands or suctioning around his tracheotomy - and that is wonderful instead of just sitting there. We were also really up and positive when the neurosurgeon smiled at us because that doesn't usually happen.

The core concept contentment with uplifting engagements also surfaced with some participants' descriptions of sharing experiences with other patients' families and friends who were also waiting. For instance, one person stated,

In this experience of waiting ... you look around at other people, and you see them looking very sad and they're alone. I find myself reaching out to all these other people. They respond immediately. It's incredible-we're all human. Sometimes I go over and touch their shoulder, and they look up with tears in their eyes and they thank me. It's just about touching the person-you don't even have to say anything. We have made human contacts with many families, and there is just this wonderful closeness. It gives me strength. It's unbelievable. I think learning to express feelings, even with strangers, is an incredible experience, a positive experience, even though what is happening is tragic and sad.

Similarly, a person whose mother was in the critical care unit shared,

After a number of weeks you tend to watch what is going on around you, and you connect with other people. We tried to show support to other patients' families by listening to them when they talked about their stories and about what had happened. For me it was a healing thing to do, to share with other people when they were open to it. 
She went on to say,

The waiting area is a place where you can sleep if you have to, or you can go for a walk if you need a release. I find simple pleasures in watching the elevators run. It is nice to have a diversion in the room ... and we [also] found humor. It would just make the time more enjoyable, and, you know, we would sit there and we would be laughing away, and it would sort of hit you that you are sitting in a critical care waiting room and you are laughing. The waiting room is a beautiful environment, and the sun warms the room. It is grounding to feel the sun and see the plants. You are out in left field, and all these things that ground you are important.

\section{DISCUSSION}

In this section each of the core concepts is further explicated in light of relevant theoretical and research literature for the purpose of enhancing understanding of the experience of waiting and contributing to the knowledge base of nursing.

\section{Vigilant Attentiveness}

The core concept vigilant attentiveness signifies the participants' descriptions of waiting as an experience of having to maintain a continuous, focused awareness and dedication to knowing what is happening and to being with their family member or friend as much as possible. At the structural transposition level the ideas captured by the core concept vigilant attentiveness are conceptualized as persistent watchfulness. Persistent watchfulness is conceptually integrated with the human becoming theory as imaging. Discussion of vigilant attentiveness as imaging sheds light on the ways people think about their realities and contributes knowledge about what images are important for people practicing persistent watchfulness.

Imaging refers to knowing at both explicit and tacit realms all at once (Parse, 1981, 1992, 1998) and can include creative imagining, which is "the picturing of what a situation might be like if lived in a particular way" (Parse, 1990, p. 138). The descriptions by the participants in this study of waiting - which led to the core concept vigilant attentiveness-illuminated their experience of wanting to maintain a continuous and focused awareness and dedication to knowing what was happening and to being as close to their loved one as possible. They said that when they were distracted at home or in a waiting room separated from their loved one, "all kinds of things were going on" in their heads as they pictured what was happening - "always anticipating a horrible event," "expecting to hear something terrible had happened," or "thinking the worst."

The core concept vigilant attentiveness is similar to notions discussed in other literature connected with the experience of waiting when a friend or family member is in critical condition. For instance, in describing the experience of family members of patients waiting for a lung transplant, Bright et al. (1990) suggested that some families feel guilty when they can't be available for their loved one. Some participants in the current study spoke about their experience of waiting in a similar way. One person shared that she felt guilty if she forgot about her son's situation, even for a moment. Similarly, Ruppert (1992) conducted a phenomenological study to describe the lived experience of wives whose husbands were hospitalized in critical care units. Ruppert said that common themes that emerged from her data yielded the category vigilance. Similar to the participants in this study, the participants in Ruppert's study described having to maintain a constant watch, being fearful of leaving, and feeling guilty if they did leave. Also similar to the participants in the current study, the participants in Ruppert's study spoke about establishing routines, which included being at the hospital most of the time, going home and coming back day after day, and being unable to concentrate on other responsibilities.

\section{Ambiguous Turbulent Lull}

The core concept ambiguous turbulent lull reflects the way participants described waiting as an uncertain and arduous experience of abeyance. At the structural transposition level the ideas captured by the core concept ambiguous turbulent lull are conceptualized as an irresolute tumultuous quietude. They are conceptually integrated with human becoming as originating. Discussion of ambiguous turbulent lull in light of the concept originating contributes to the general understanding of originating and furthers knowledge about the lived experience of waiting.

Originating is related to the ways humans create ways of distinguishing and living their personal uniqueness while simultaneously designing ways to go along with and be like others. As humans originate ways of being the same yet unique, they are both sure about the choices they 
make and unsure what the outcomes of those choices will be (Parse, 1981, 1998).

In this study the participants' descriptions that led to the core concept ambiguous turbulent lull are an example of the torment that people experience when choosing to conform with a system that has kept them separated from their loved ones. The participants spoke about finding ways to conform with the rules in the critical care waiting room-rules about when they could see their loved ones, about who to ask for permission to enter the critical care unit, and about how to go about getting the information they needed. The descriptions also illuminate the extreme difficulty, even agony, of knowing with certainty what one wants to have happen-yet being entirely uncertain and terrified about how the situation will unfold.

The core concept ambiguous turbulent lull is not explicitly named in other literature; however, the major ideas this core concept represents are generally alluded to and are consistent with the findings of several other studies focused on the experiences of family members in a critical care waiting room. For instance, others have connected either waiting or the experience of being in a critical care waiting room with uncertainty, fear, frustration, anguish, and distress (Bright et al., 1990; Bunzel et al., 1992; Dube et al., 1991; Leske, 1992; Ruppert, 1992). These descriptors are similar to the ambiguity and turbulence captured by this core concept. However, the findings from this current study add the understanding that people waiting for a friend or family member in critical condition not only describe experiencing a whirlwind of uncertainty, anguish, and doubt, they also describe experiences that can be conceptualized as a lull. For instance, some spoke of feeling "like time has stopped" or that "[time] absolutely stands still, that it's like being paralyzed," like their "life has stopped."

\section{Contentment With Uplifting Engagements}

The core concept contentment with uplifting engagements represents the participants' descriptions of soothing and heartening patterns of relating with others, activities, and objects. At the structural transposition level the ideas central to contentment with uplifting engagements are conceptualized as satisfaction with fortifying involvements. Satisfaction with fortifying involvements is conceptually integrated with the human becoming theory as connecting-separat- ing. Exploration of contentment with uplifting engagements in light of the theoretical concept connecting-separating enhances understanding of this concept and adds further depth and clarity to knowledge about waiting.

Connecting-separating, a concept of the second principle of human becoming, is the paradoxical rhythm of being with and away from others, ideas, objects, and events (Parse, 1981, 1998). When the participants in this study spoke of waiting in ways that led the researchers to the core concept contentment with uplifting engagements, they talked about being with and away from their loved ones, as well as being with and away from other families, activities, their own families, or various aspects of their lives. They spoke of connecting with the person in critical condition, while all at once separating from that person. They described experiences of humor and comfort while connecting with others and events and activities that were "uplifting," "grounding," or "joyful," (yet all-at-once separating themselves) from ideas and people and activities that distracted them from the situation.

The core concept contentment with uplifting engagements is similar to ideas found in the extant literature that emphasize the importance of equitable care, dignity, respect (Waters, 1999), assurance, support, and comfort for family members in a critical care waiting room (Warren, 1993, 1994). Similar to many of the participants in this current study, the participants in Ruppert's (1992) study spoke about seeking information, gathering support, and sharing experiences with others. In that study as well as the current one, participants said that it helped them to be able to receive information and to be involved in their loved one's care. The findings from this current study add to the literature the understanding that amid the tumultuous uncertainty of the unwelcome stillness, people can simultaneously describe waiting as bringing contentment and being satisfying and comforting. The paradoxical nature of human experience was eloquently illuminated by some of the descriptions of waiting that led to this core concept; for instance, amid their "anguish" and "distress," participants said there were also moments of "joy and laughter" and "incredible positive experiences."

\section{Recommendations for Future Research}

In addition to further research on the lived experience of waiting, many possibilities for future 
investigations can be gleaned from the core concepts that emerged in this study. The first core concept, vigilant attentiveness, might lead one to investigate universal lived experiences such as focusing on something important, being attentive to another, or imagining the worst. Understanding of the second core concept, ambiguous turbulent lull, could be enhanced further by investigating universal lived experiences like being afraid, feeling numb, being unsure, or worrying about what will happen. The third core concept, contentment with uplifting engagements, might lead to further investigations on contentment or feeling calm. Research on any of these phenomena or others has the potential to add to a general understanding about the experience of waiting and to contribute to knowledge about human becoming.

\section{Recommendations for Practice}

The findings of this study enhance knowledge about human becoming - a knowledge base that when integrated can help nurses practice in ways that enhance opportunities for understanding and discovery. The human becoming theory helps define the intent and purpose of the nurse-person process.

The conclusions drawn from this research study contribute to a general understanding of several of the major concepts of the theory. By making explicit the connections between the core concepts of this study and the concepts imaging, originating, and connecting-separating, as has been done through this study, depth and clarity have been added to the knowledge of concepts that can help nurses to understand the theory in more concrete ways and to be better able to live it in practice. Specifically, the findings may help nurses:

1. Be available to hearing the perspectives of others about the experience of picturing what might happen while waiting-and to structure practice in ways that honor those perspectives and address what the persons say is helpful.

2. Have a better understanding of what it is like for people to choose to conform/not conform with systems and rules that keep them separated from their loved ones amid tormenting uncertainty-and to reflect on the policies and practices currently in place in waiting areas that restrict visiting hours, make family leave their loved one's bedside for even minor procedures, and require family to call into the unit for "permission to enter" only to have to wait for long periods, sometimes hours, for a response.

3. Respect and accommodate persons' desires to be with and away from their loved ones-and to address and support what persons say is helpful or not helpful. Telling people to go home and rest or controlling when they can visit often is not helpful. Sometimes people just want to be present with or to participate in the care of their loved one.

\section{CONCLUSIONS}

New knowledge has been provided by this study about what it is like for people to wait.

1. It synthesizes the essences of the experience of waiting for the participants in this study into a unique definition: Waiting is a vigilant attentiveness surfacing amid an ambiguous turbulent lull as contentment emerges with uplifting engagements.

2. It contributes the idea that waiting is a paradoxical human experience of turbulence/ stillness all at once.

3. It illustrates that contentment intermingles with the ambiguity and turbulence of waiting.

This study contributes to a growing knowledge base that supports the idea that understanding the lived experiences of persons is essential for providing quality health care services. The findings are useful for professionals concerned with health, quality of life, and quality of health care for persons waiting while someone close to them is in a critical care unit. This results of this study also add to general knowledge about the human lived experience and enhance general understanding about human becoming that can be used to guide future research and practice.

\section{REFERENCES}

Bright, M.J., Craven, J.L., \& Kelley, P.J. (1990). Assessment and management of psychosocial stress in lung transplant candidates. Health and Social Work, 15, 125-132.

Bruce, T.A., Bowman, J.M., \& Brown, S.T. (1998). Factors that influence patient satisfaction in the emergency department. Journal of Nursing Care Quality, 13(2), 31-37.

Bunzel, B., Wollenek, G., \& Grundbock, A. (1992). Psychosocial problems of donor heart recipients 
adversely affecting quality of life. Quality of Life Research, 1, 307-313.

Dube, L., Schmitt, B.H., \& Leclerc, F. (1991). Consumers' affective response to delays at different phases of service delivery. Journal of Applied Social Psychology, 21, 810-820.

Giorgi, A. (1985). Sketch of a psychological phenomenological method. In A. Giorgi (Ed.), Phenomenology and psychological research (pp. 8-22). Pittsburgh, PA: Duquesne University Press.

Giorgi, A. (1989). One type of analysis of descriptive data: Procedures involved in following a systematic phenomenological method. Annual Edition of Methods: A Journal for Human Science, $39-61$.

Giorgi, A. (1997). The theory, practice, and evaluation of the phenomenological method as a qualitative research procedure. Journal of Phenomenological Psychology, 28, 235-260.

Leske, J.S. (1992). The impact of critical injury as described by a spouse: A retrospective case study. Clinical Nursing Research, 1, 385-401.

Parse, R.R. (1981). Man-living-health: A theory of nursing. New York: Wiley.

Parse, R.R. (1987). Nursing science: Major paradigms, theories, and critiques. Philadelphia: W.B. Saunders.

Parse, R.R. (1990). Health: A personal commitment. Nursing Science Quarterly, 3, 136-140.

Parse, R.R. (1992). Human becoming: Parse's theory of nursing. Nursing Science Quarterly, 5, 35-42.

Parse, R.R. (1994). Quality of life: Sciencing and living the art of human becoming. Nursing Science Quarterly, 7, 16-21.

Parse, R.R. (1998). The human becoming school of thought. Thousand Oaks, CA: Sage.

Parse, R.R. (2001). Qualitative inquiry: The path of sciencing. Sudbury, MA: Jones \& Bartlett.
Rondeau, K.V. (1998). Managing the clinic wait: An important quality of care challenge. Journal of Nursing Care Quality, 13(2), 11-20.

Ruppert, S.D. (1992). Wives' perceptions of situational experiences during critical care hospitalization: A phenomenological study. (Doctoral dissertation, Texas Woman's University, 1992). Dissertation Abstracts International, 54, 01B169.

Seuss, Dr. (1990). Oh, the places you'll go! New York: Random House.

Spiegelberg, H. (1965). The phenomenological movement: A historical introduction: Vol. 1 (2nd ed., pp. 653-701). The Hague, The Netherlands: Martinus Nijhoff. (Original work published 1960).

Spiegelberg, H. (1975). Doing phenomenology: Essays on and in phenomenology. The Hague, The Netherlands: Martinus Nijhoff.

Spiegelberg, H. (1976). The phenomenological movement (Vols. I-II). The Hague, The Netherlands: Martinus Nijhof.

Suszycki, L.H. (1988). Psychosocial aspects of heart transplantation. Social Work, 33, 205-209.

van Kaam, A.L. (1959). Phenomenal analysis: Exemplified by a study of the experience of "feeling really understood." Journal of Individual Psychology, 15, 66-72.

van Kaam, A.L. (1966). Existential foundations of psychology (pp. 294-329). Pittsburgh, PA: Duquesne University Press.

Warren, N.A. (1993). Perceived needs of family members in the critical care waiting room. Critical Care Nursing Quarterly, 16(3), 56-63.

Warren, N.A. (1994). The phenomena of nurses' caring behaviors as perceived by the critical care family. Critical Care Nursing Quarterly, 17(3), 67-72.

Waters, C.M. (1999). Professional nursing support for culturally diverse family members of critically ill adults. Research in Nursing \& Health, 22, 107-117. 